

Citation:

Burnett, L (2019) What if: the literary case for more climate change. Interdisciplinary Studies in Literature and Environment. ISSN 1076-0962 DOI: https://doi.org/10.1093/isle/isz002

Link to Leeds Beckett Repository record:

https://eprints.leedsbeckett.ac.uk/id/eprint/5045/

Document Version:

Article (Accepted Version)

This is a pre-copyedited, author-produced version of an article accepted for publication in Interdisciplinary Studies in Literature and Environment following peer review. The version of record Burnett, L. What If: The Literary Case for More Climate Change, ISLE: Interdisciplinary Studies in Literature and Environment, isz002, is available online at: https://academic.oup.com/isle/advancearticle-abstract/doi/10.1093/isle/isz002.

The aim of the Leeds Beckett Repository is to provide open access to our research, as required by funder policies and permitted by publishers and copyright law.

The Leeds Beckett repository holds a wide range of publications, each of which has been checked for copyright and the relevant embargo period has been applied by the Research Services team.

We operate on a standard take-down policy. If you are the author or publisher of an output and you would like it removed from the repository, please contact us and we will investigate on a case-by-case basis.

Each thesis in the repository has been cleared where necessary by the author for third party copyright. If you would like a thesis to be removed from the repository or believe there is an issue with copyright, please contact us on openaccess@leedsbeckett.ac.uk and we will investigate on a case-by-case basis. 


\title{
What if: the literary case for more climate change
}

\section{Dr Lucy Burnett, Leeds Beckett University}

\begin{abstract}
:
In recent years, contemporary climate change discourse has become dominated by the trope 'what if'. Yet far from operating such as to open up new ways of thinking, across political scientific and literary spheres, answers to the trope close down around accounts of catastrophe, framed by a mitigation agenda intent on solving the problem before it's too late. This paper critiques the ideological problems associated with this perspective on climate change, and presents a provocative three-part literary manifesto which explores how creative literary practice might explore 'more climate change' as opposed to 'less'.
\end{abstract}




\section{Part I - the creative deficit of 'less' climate change}

What if there is more than two degrees of global warming? What if the Gulf Stream stops? What if we encounter abrupt climate change? What if there is sufficient sea level rise to make certain states and countries, such as the Polynesian island of Tuvalu, uninhabitable? The tenor of contemporary climate change discourse is best captured by the trope 'what if...?' Such questions have provided the basis for decades of United Nations negotiation aimed at avoiding the worst-case scenarios, or indeed 'solving' climate change itself. These debates are informed by the scoping reports of the Intergovernmental Panel on Climate Change (IPCC), which project outcomes forward from a range of possible scenarios. And, in a broader cultural context, plotting these 'what if' scenarios has been a dominant vision of climate change among writers, film-makers and other artists, perhaps most famously captured in the fictional blockbuster The Day After Tomorrow, which asks: 'what if' ocean circulation patterns become disrupted and usher in severe climatic change?

Coming at climate change myself, as a writer and former professional environmental campaigner, the trope creatively appeals for its potential to suggest new ways of thinking about an issue where stalemate has so frequently prevailed. In literature, 'what if' questions enable writers and readers to imagine what might or could happen under certain (more or less likely) circumstances, even if such flights of the imagination appear implausible. Fantasy and surprise are key characteristics of such texts, with Lewis Carroll's Alice in Wonderland and Through the Looking Glass two typical examples which have proven particularly influential upon my own practice. 'What if' Alice fell down a rabbit hole, or 'what if' she travelled through the reversing qualities of the looking glass? It would be impossible to predict what happens next, although a distinct logic makes the narrative believable and carries the reader along. In turn, while imagination might not be the quality immediately associated with good science, many scientific enquiries apply the 'what if' methodology in very similar ways - as open-ended investigations with the aim of literally seeing what happens if you do this. Common to both is the notion of experiment. 
If only, when it comes to climate change, the trope operated in such open-ended ways. For, far from offering a kaleidoscopic array of new ways of thinking, answers to the question 'what if' climate change - across politics, science and culture - close down around versions of the same scenario, as if the answer to the trope had already been decided before we asked the question. According to this consensus, climate change is a catastrophe waiting to happen, framed by a climate mitigation agenda intent on 'solving' the problem before it's too late. Indeed, I propose that this way of framing climate change has been repeated so frequently that it has come to broadly constitute what climate change means, across culture and science.

Yet teleological climate mitigation is no more the only approach which science might take to climate change, than the emergent conventions of climate literary genre are the only possible forms of cultural response. I can imagine, for example, a science dedicated to approaching how we might live more environmentally with our climate - a processual methodology in contrast to the ends-driven one which dominates the IPCC research model. And similarly to how this consensus determines the kind of science applied to climate, in a parallel journal article to this one, 'Firing the Climate Canon: A Critique of the Literary Genre of Climate Change' (Burnett 2018), I utilise frame analysis and genre theory to show how a dominant frame of climate change has become mapped onto the literary canon's content and form in a wide range of popular science books ${ }^{1}$, novels ${ }^{2}$ and poetry anthologies:

[Utilising] John Frow's breakdown of genre into the four main criteria of function, content, mode and form, [I] demonstrate an inexact but instructive process of mapping from the dominant frame of climate change onto mainstream generic conventions across the forms of popular science literature, fiction and poetry. My aim is not to enact a range of value judgements. Furthermore, my process of analysis is partial, and its broad sweep will inevitably brush over many nuances and complexities. Instead, my aims are provocative: to draw out broad trends with a view to making the case (and space) for something radically 'other', which reaches well beyond the limitations of the dominant frame.

\footnotetext{
${ }^{1}$ Al Gore The Inconvenient Truth (2006), James Lovelock The Revenge of Gaia (2007), Mark Lynas High Tide (2005), Alistair McIntosh Hell or High Water (2008) and George Monbiot Heat: How We Can Stop the Planet Burning (2007b)

${ }^{2}$ Cormac McCarthy The Road (2006), Jeanette Winterson The Stone Gods (2007), Will Self The Book of Dave (2007), Sarah Hall The Carhullan Army (2007), Kim Stanley Robinson Sixty Days and Counting (2007), Liz Jensen The Rapture (2009), Matthew Glass Ultimatum (2009), Margaret Atwood Year of the Flood (2010) and Ian McEwan Solar (2010)

${ }^{3}$ Earth Shattering (Astley 2007), Trees in the City (Poet in the City 2007), Feeling the Pressure (Munden 2008) and And This Global Warming (Aman Awel Tawe 2012)
} 
As this paper argues, even Cormac McCarthy's The Road, which might seem like an interesting exception to the above conventions (not least since McCarthy went to such lengths to avoid identifying the cause of his post-apocalyptic world) is subjected to the above logic. George Monbiot's reading (2007) of it as the best climate change novel is perhaps disingenuous, but inevitable, since The Road mobilises the full range of representational conventions I identify with the climate change 'genre'.

There is not space here to revisit the nuances of this extended genre analysis, and the different mappings which stem from it, but The Day After Tomorrow provides a prototypical example. Ursula Heise's critique of the 'formulaic' structure of climate change literature (206) may be sweeping, but rightfully highlights the 'canon's' lack of formal innovation in response to climate change's complexity. In The Day After Tomorrow, an Aristotelian structure of conflict, crisis and resolution directly maps the diagnosis (climate change is real), prognosis (it is going to be catastrophic), and motivational (we must act urgently) dynamics of the dominant frame. Meanwhile, the impossibility of representing climate change itself is sidestepped through representations of the political machinations of a world on the brink of disaster. The US Vice President fails to take heed of a climate scientist's warning of abrupt climate change come true: a worsening sequence of tornadoes, floods and superstorms sweep across America, leading to mass evacuation to Mexico and leaving a trail of near-apocalyptic destruction in its wake. Yet despite evoking end-of-the-world imaginaries, the film still manages to find 'resolution'. The Vice President addresses the nation from exile, while astronauts look down from space upon a virginally pristine Earth. In the context of such devastation, the implied optimism that humanity might prevail in the final analysis seems at best peculiar, if not seriously misplaced. However, on closer reflection, does it not in actual fact stage a third key component of the dominant frame, because without an underlying belief that humanity can and should prevail over climate change, is the entire mitigation agenda not groundless?

Climate change politics, and the environmental movement, are frequently considered radical, emancipatory agendas. On the contrary, this residual confidence is symptomatic of their continued rootedness in longestablished ideological narratives of human mastery and progress. For, is the assumption that we might 
somehow solve climate change not the apotheosis of the human hubris that got us into this situation in the first place - based upon an untenable dualist separation from a climate we might somehow stabilise? According to Erik Swyngedouw, far from driving forward a progressive agenda, the apocalyptic framing of climate change discourse dis-empowers the public in the interests of the neo-liberal, capitalist status quo:

Our ecological predicament is sutured by millennial fears, sustained by an apocalyptic rhetoric and representational tactics, and by a series of performative gestures signalling an overwhelming, mindboggling danger, one that threatens to undermine the very coordinates of our everyday lives and routines, and may shake up the foundations of all we took and take for granted. [...] I would argue that sustaining and nurturing apocalyptic imaginaries is an integral and vital part of the new cultural politics of capitalism for which the management of fear is a central leitmotif. (218)

Furthermore, as frame analysts point out (Reese et al, Snow \& Benford, Kuypers), ideological consensuses such as this work to legitimate some activities and de-legitimate others, prompting me to thereby ask: what if what is needed right now is not less climate change, as is commonly assumed, but rather more of it? Here I am not defining 'climate' in the conventional currency, as a statistical average of weather conditions, but rather referring to the prevailing ideologies, frameworks and cultural norms that inform our understanding of environmental change in the first place. Eco-philosopher Timothy Morton has argued that, 'one thing that modernity has damaged, along with the environment, has been thinking.' (2010a 1) And this certainly seems to have been the case here. When it comes to climate change, the seriousness of its potential consequences are considered sufficient reason to short-circuit thinking through the imperative to 'act now' before it's too late, in a peculiar inverse of the logic that supposes more serious issues require more thought, not less. Or perhaps more accurately, when it comes to climate change we discover that the majority of the thinking has already been done for us. When we are asked to 'act', what we are really being asked to do is to accept a certain framework for understanding and to act accordingly.

In contrast, a world of 'more climate change' would be characterised by more thinking, and its thought processes would have more in common with what Timothy Morton describes as Sunday afternoon thinking than the teleological approaches outlined above: 
I've been accused of not wanting to help Katrina victims because I'm so busy theorising with my head in the clouds: 'your ideas are all very well for a lazy Sunday afternoon, but out here in the real world, what are we actually going to do?' Yet one thing we must precisely do is break down the distinction between Sunday afternoon and every other day, and in the direction of putting a bit of Sunday afternoon into Monday morning, rather than making Sunday a workday. (2010b Kindle Loc 1526)

British climatologist Mike Hulme's conclusion to Why We Disagree About Climate Change is characteristic of 'more climate change' thinking, and proved particularly enabling of my own creative explorations. For Hulme, solving climate change is in fact impossible, since it has extended far beyond its scientific origins into an overarching 'idea': a metanarrative that can no more be solved than religion (330-340). In this context, he proposes that we might more helpfully view climate change instead as an invitation to ask more fundamental questions about the meaning of the human project on Earth: 'rather than catalysing disagreements about how, when and where to tackle climate change, the idea of climate change should be seen as an intellectual resource around which our collective and personal identities and projects take shape.' (326) Together with the myth of Icarus (whose tale of hubris I had started to associate with climate change) and my bicycle (an abiding creative tool), this invitation helped conceive the 'what if' question that became the starting point of my subsequent creative enquiries: what if I set off on my bicycle, from my home in Salford to the Greek island of Icaria (where Icarus supposedly fell) to see whether I could improvise a more sustainable route across Europe than Icarus managed?

In the body of this article I present a literary manifesto of 'more climate change'. My own creative practice and findings frequently provide examples, alongside an eclectic range of texts which prove helpful not least because they are not about climate change. Of course, my work is partial and specific - an account of how I sought an alternative response to climate change during the writing of Through the Weather Glass, the hybrid novel which tells a fantastical version of the above expedition through the story of a female Icarus and a talking bicycle, quested across Europe in search of 'solutions' to climate change.

Dear Icarus. Your attendance is requested at an extraordinary Athenian people's democracy tasked with resolving climate change, and discovering a future for this troubled earth, to be held on the $9^{\text {th }}$ of September 2010 at the Pnyx, Athens. May this be a test of your ability to rewrite your fate. In 
anticipation, Zeus (Burnett 2015 23)

Neither are the non-climate texts, through which I seek to extend the climate change oeuvre, exclusive examples, nor exemplars nor models. They are simply the texts I personally found most useful. Rather, I ask: what if we cross climate change with an eclectic range of books such as Through the Looking Glass, the myth of Icarus, Karen Barad's theories, and Zen and the Art of Motorcycle Maintenance? Furthermore, presenting this as a manifesto is a tongue-in-cheek provocation not a diktat, for in a world of 'more climate change' there can be no one approach. I wouldn't expect anyone, let alone everyone, to undertake a 2500 mile cycle as a means of working through their response to climate change (indeed few people might consider this a Sunday afternoon wander)! However, I do propose that others devise their own journeys of enquiry. How might your Sundayafternoon wanders through the thought clouds of 'more climate change' proceed, and what books might provide your textual points of reference? Where might our combined experiments with, and literary extensions of, climate change lead? And how can cultural explorations such as those I explore here run in productive parallel with similarly open-ended scientific lines of climate enquiry?

\section{Part II - a post-climate change literary manifesto of 'more climate change'}

\section{i. open-endedness, improvisation, play}

During my early creative enquiries into climate change, feeling blocked into a corner by perceiving that climate change required me to subvert my aesthetics for didactic ends, I asked an ecocritical symposium: ‘how can I write an improvised, playful poetics which explores serious, politically involved issues such as climate change, without trivialising them?' No one had an answer then. Yet, where improvisation and playfulness once seemed inappropriate responses to climate catastrophe, in a world of 'more climate change' they become key attributes of an open-ended poetics conducted in an epistemological spirit of humility and curiosity. On the one hand they are important for enabling us to adapt to the challenges which will undoubtedly come: 
If the abrupt climate change thesis has a lesson, it is surely as much about the way that extreme conditions condemn us and other creatures to experimentation and improvisation as it is about the need for precaution and self-restraint. (Clark 49-50)

However, they also productively important in enabling space for new, unexpected meanings and encounters which our conscious minds might be unable to straightforwardly access. Poet Cliff Yates defines improvisation as writing such 'as to tap into the potential of the material, as it unfolds, to suggest further possibilities not necessarily anticipated at the beginning.' (29) The aim is to surpass pre-determined patterns of thinking, through writing 'without a set idea of where the poem is heading. As if the poem has a life, or energy, of its own.' (28). Certainly, this risks leading us where we do not wish to go, but as Picasso famously said, 'if you know exactly what you are going to do, what is the point in doing it?' (qtd in Yates 29) Or qua Apollinaire: 'surprise is the greatest source of what is new.' (qtd in Yates 29) In turn, by proposing a 'playful' poetics I envisage a Derridean de-centring of the human project, an ability to laugh at our assumptions of human mastery, and work informed by a positive spirit of curiosity and humility, not discovery and control (in both cultural and scientific contexts). The contrast between 'work' and 'play' echoes Timothy Morton's comparison of Monday and Sunday forms of thinking, and an unsettling of teleological thought processes.

Admittedly, when it comes to climate change, where patterns of thinking have become engrained, improvisation proves difficult. However, various devices and techniques such as the open-ended application of the 'what if' trope, collage, and chance-processes, can help writers access the desired quality of 'surprise'. Turning to my first unlikely example in the case of climate change, in Through the Looking Glass, Lewis Carroll's improvisatory approach to the 'what if' trope contrasts starkly with the dynamics of climate closure outlined above. What if, rather than staring at her own reflection in the mirror, Alice travels through the looking glass into the world beyond?

“Now, if you'll only attend Kitty, I'll tell you all about Looking-glass house. First, there's the room you can see through the glass - that's just the same as our drawing room, only the things go the other way...Well then, the books are something like our books, except the words go the wrong way: I know 
that because I've held up one of our books to the glass, and then they hold one up in the other room. (Carroll 125-6)

Through the mirror, Alice's adventures in looking glass world are informed by this logic of reversal: left-right reversals such as the White Knight squeezing a right foot into a left shoe, asymmetric reversals such as Alice walking backwards to approach the Red Queen, and the more conceptual reversal of 'sense' into 'nonsense' (Gardner 148-9). Yet, this never feels like a pre-determined vision. Rather, through a combination of Alice's eye-level perspective, complication by other logical processes (like chess), and a spirit of epistemological curiosity, Carroll, Alice and readers find out about the looking glass world as they go. In contrast to 'endsdriven' thinking, Alice's behaviour is informed by the motto, 'curiouser and curiouser!' as she famously remarks during her Adventures in Wonderland (Carroll 16). Furthermore, Carroll's Alice books epitomise playfulness. The entire adventure is framed as Alice engaging in 'child's-play', while in fact enacting a sustained critique of (poking fun at) the notion of human 'progress'.

Through the Weather Glass is variously indebted to Carroll, including applying 'what if' questions in improvisatory ways. My own 'novel' enfolds three 'what if' questions upon one other to maintain the quality of openness. When I set off cycling, I had no idea whether I would even make it, let alone whether my findings would prove relevant to climate change. Yet when it came to writing, a further 'what if' question was required, to prevent the narrative closing down around a straightforward travelogue, which radically re-frames the autobiographical narrative in fantastical terms. 'What if' Icarus were pushed off Planet Zeus, got pulverised by the greenhouse effect while tumbling through the atmosphere, landed back on Earth as an amoeba, only to re-form as a woman and be told by a nearby talking bicycle that Zeus has sent them on a trans-European adventure in search of a solution to climate change? In turn, it was only while free-writing this fictionalised account that I 'found' the 'what if' trope which not only upturns the quest, but provides the book's Carrollian conceptual heart. What if, instead of staring at our own reflections in the weather glass (an ancient barometric device here symbolising climate change), we travel through everything we know about climate change and participate in the weather glass world beyond? If the reversing qualities of the mirror provide the informing logic of Through the Looking Glass, how might a genuine, embodied appreciation of climate change alter our understanding and response? 
'You've got to look at this!' Icarus exclaimed.

W [the bicycle] proved unwilling, but when he did [look through the weather glass] he drew his tyre pressure in sharply. 'Wow. It's like viewing the world from the perspective of the sky.'

Icarus removed her single novel from her bag and held it before her. Through the Looking Glass. Through the Weather Glass. Had she been so busy staring at her own reflection in the glass that she had failed to read its invitation through - into the climate changing world beyond? (Burnett 2015 157)

Already by the start of the novel, Icarus is tired of her reincarnated tale of hubristic tragedy, and wishes to rewrite her fate - only to be sent on a quest whose aims of solving climate change are the epitome of Icarian hubris! By travelling through the weather glass, Icarus and $\mathrm{W}$ not only perform an improvised response through the skies of Italy, but the writing itself changes from the predominant cross-form approach (shifting between prose, poetry and photography) to an extended collage composed by writing my own narrative of my cycle through Italy, Through the Looking Glass and an IPCC climate change report (Pauchari \& Resinger) through each other:

one thing was unequivocal

flying my imagination into

a warming climate was nothing like

having my face washed by an old cat

as is now observationally evident

language could have had no hand in the mischief

it was the weather's fault entirely (163)

Lewis Carroll's playful tone pervades the poem, while the novel is more broadly populated with talking bicycles and carbon dioxide particles, and cameos by Mary Queen of Scots, Asterix, Zeus, Da Vinci and others. Where Carroll pokes fun at human progress, Through the Weather Glass enacts a lighthearted but sustained critique of our conventional response to climate change. The mitigation agenda is playfully interrogated during banter between Icarus and her climate-change geek of a bicycle, who plans to 'solve' climate change through pedal-power alone. Meanwhile, towards the end of the novel, processes of chance are used to rewrite 
Raymond Queneau's tale in The Flight of Icarus about a writer losing their lead character as an environmentalist who has lost the sky:

'Perhaps that is how it will be for all of us, one day. We won't have any more skies. We will become environmentalists in search of skies. The environment will perhaps not be dead, but it won't have skies in it any more. Difficult to imagine, an environment without skies. But isn't all progress, if progress exists, difficult to imagine?' (308)

Yet equally crucially, the 'novel' self-deprecatingly pokes fun at my own / Icarus's failings and presumptions - not least my own problematic assumption that I could cycle fully-loaded over the Alps, and Icarus's awareness of her limitations when informed about the quest: 'Icarus read the invitation once, twice, while its implications scaled her rebuilt spine, and her eyebrows circumnavigated the moon. No! Had Zeus lost the plot?' (23)

Nonetheless, Icarus's curiosity leads her on a journey through climate change such that she does arrive in Athens with something to 'say', even if the questions she poses differ from the 'solutions' Zeus wishes for. Furthermore, processes of improvisation and play prove crucial to Icarus's and my own 'findings'. The idea of weather glass world originally emerged through free-writing. Meanwhile, performing my experiences of Italy through the perspective of the weather glass brought into clear focus the relationship between our ideological framing of climate change and a wide range of other issues, such as gender. In the following fragment Icarus reflects upon her increasingly hostile reception having fallen back through climate change into Greece:

At what price the weather glass traveller in a world that otherwise remained unchanged? Icarus felt not only cut-out, but cut-up, where the world's hubris and ends-oriented ambitions and machismo and capitalist greed and fear of apocalypse had self-harmed on her.' (207)

Far from Icarus's sex change being a cruel trick played upon her by Apollo as initially supposed, and certainly not seeking to propose that women might somehow be better equipped to respond to climate change, instead Icarus realises that gender and climate change are both negotiable factors in the re/deconstruction of her own 
changing identity. Furthermore, both can themselves be reconfigured when considered from an alternative perspective than the patriarchal, ideological norms of human mastery and progress.

\section{ii. intra-(formalism, genericism, textuality)}

If, as per Mike Hulme, climate change is unprecedentedly complex, and entangled in every aspect of human life, then this demands an equally complex and entangled formal response - not as a weak form of mimeticism, but as a performative gesture towards the heterogeneous dynamics involved. A poetics of 'more climate change' will share characteristics with what Timothy Morton coins 'the mesh' (2010b Kindle Location 119) to capture the vast web of semiotic and biosemiotic exchanges which make up an inextricably entangled world. On the one hand this implies an ambitious, extended aesthetic, for writers are posed the formal challenge of incorporating and responding to everything - a large scale re-apprehension of climate change, its disruptions and contradictions which can only ever be an endless work in progress. More important still, writers are responsible for how they negotiate this mesh. Where the literature of 'less climate change' is led by content representations of what climate change looks like - the literature of 'more climate change' stages the dynamic relationship between form and content in the re-making of climate change. In this section I consider form, genre and intertextuality through a 'more climate change' reading of cultural theorist and quantum physicist Karen Barad.

For Barad, the world is not composed of pre-existent entities which interact. Rather, it is the dynamic intraactions of material and discursive practices which comprise reality, with phenomena, including subjects and objects, humans and nonhumans, culture and nature, emerging from within the exclusions and boundarymaking practices involved. 'Relata do not pre-exist relations; rather, relata-within-phenomenon emerge through specific intra-actions.' (139-140) The notion of the 'cut' is key to the construction of contingent boundaries:

Wholeness, according to agential realism, does not signify the dissolution of boundaries. On the contrary, boundaries are necessary for making meanings [...] Furthermore, boundaries are not fixed. 
Productive and creative tensions are set up in consideration of different possible placements of agentially situated cuts. (182)

Since we inextricably participate in co-becoming, and since during this process we 'enact' constitutive cuts, we are ethically responsible for what we make and unmake possible, and our actions are capable of achieving change: 'particular possibilities for (intra-acting) exist at every moment, and these changing possibilities entail an ethical obligation to intra-act responsibly in the world's becoming, to contest and rework what matters and what is excluded from mattering.' (178) Indeed Barad's underlying motivation to 'change the possibilities of change' (178) chimes strongly with the ethos of 'more climate change'. In this case, rather than viewing ourselves in separate relation to a climate we will manage and 'solve', attention re-focusses on our coemergence with it. During this process we enact a range of 'cuts' (and are ourselves cut upon) which either reinforce ('less climate change') or challenge ('more climate change') established boundaries. Not only are we inherently responsible for these cuts, but the dynamics are continuous, unavoidable, and materially significant of both climate change and our own identities. Interpreting this within a literary context, I propose that this process of 'cutting' is achieved through the apparatuses of form and genre during climate change's textual materialisation with and from other works. I coin the terms intra-formalism, intra-genericism and intratextuality to highlight the mutable and co-constituting processes involved.

The plural hybrid aesthetics of 'postlanguage' poetics, by which term Mark Wallace describes the work of himself, Lisa Jarnot, Juliana Spahr, Nick Piombimo and others (online), characterises what I propose by 'intraformality' - a poetics interested in how literary forms cut and recut the boundaries of meaning. A British precedent is Iain Sinclair's Lud Heat. Lud Heat, Sinclair's seminal psychogeographic work, explores the palimpsestic psychological, geographic and mythological construction of the London area of Ludgate. Rather than seeking to represent this locale, the work stages it as a formal experience. Academic prose is intercut with lyrical poetry and autobiography which in combinatory relation ask: what bears more significance in our negotiation of place, our psychological experience or matters of historical / geographic 'fact'? Not only is one's understanding of place expanded, the relationship between different literary forms and the subjective, the objective and the lyric voice are complicated. Furthermore, Lud Heat simultaneously carves out new space 
(now understood as psychogeography) between the genres of travel and guidebook writing, autobiography and mythology, and is thus as intra-generically experimental as it is intra-formal.

In an article I have written sits in parallel to this one, 'Firing the Climate Canon' (2018 forthcoming), I utilise theorist John Frow's summary of genre's meaning-making characteristics as the basis for my mapping of the dominant frame of climate change on to emergent generic norms in the 'climate canon'. Where frames are the means of structuring meaning in broader societal terms, genre performs the equivalent literary role:

Genre is a set of conventional and highly organised constraints on the production and interpretation of meaning. In using the word 'constraint' I don't mean to say that genre is simply a restriction. Rather, its structuring effects are productive of meaning; they shape and guide, in the way that a builder's form gives shape to a pour of concrete, or a sculptor's mould shapes and gives structure to its materials. Generic structure both enables and restricts meaning, and is a basic condition for meaning to take place. (Frow 10)

Yet just because, according to this parallel paper's argument, the 'genre' of literary climate change thus mirrors the communicative impulse of the dominant frame, this does not mean that this manoeuvre is inevitable. For genre is itself unstable, and experimenting with it is the key literary means by which writers negotiate change: read through Karen Bard, even entrenched generic conventions are open to challenge and re-emergence.

An example of what I don't mean by intra-genericism is Solar, where Ian McEwan's continued attachment to the climate mitigation agenda and its apocalyptic undertones, combined with a comedy genre, leads to an uneasy sense that our catastrophic futures really are being trivialised. At no point does McEwan challenge the climate catastrophe model of thinking. Even though the focus is on the quotidian details of a failing climate scientist, the catastrophic future provides its conceptual frame. And, within this context, the choice of a comedy genre falls down, because environmental catastrophe simply isn't funny. Instead, what I'm interested in are self-conscious performances of intra-genericism which complicate or challenge existing meanings and our construction of them. Mark Z. Danielewski's House of Leaves is not only a rare example in recent fiction of the scale, complexity and formal ambition which might usefully be turned to climate change, his attempt to do 
everything involves a heterogeneous defiance of generic boundaries. Is this a novel about criticism or a criticism of the novel, or a self-reflexive novel about self-reflexive criticism, or in fact simply a 'genuinely scary chiller' as Mark Beaumont comments on its flycover - itself a hybrid combination of thriller and horror? Taking another example, Theresa Hak Kyung Cha's Dictée unsettles questions of identity in the context of cultural subjugation (in this case Korea's occupation by Japan) through disjunctive shifts between genres. She lists Greek goddesses with their associated genres, to itinerise how the 'daughters of Zeus' might choose, yet be prevented, from telling their stories (a process which the rest of the book performs):

$\begin{array}{ll}\text { CLIO } & \text { HISTORY } \\ \text { CALLIOPE } & \text { EPIC POETRY } \\ \text { URANIA } & \text { ASTRONOMY } \\ \text { MELPOMENE } & \text { TRAGEDY } \\ \text { ERATO } & \text { LOVE POETRY } \\ \text { ELITERE } & \text { LYRIC POETRY } \\ \text { THALIA } & \text { COMEDY } \\ \text { TERPSICHORE } & \text { CHORAL DANCE } \\ \text { POLYMNIA } & \text { SACRED POETRY } \\ & \text { (preface) }\end{array}$

Intra-genericism is itself only one example of intra-textuality - a new coinage emphasising the active roles writers play in negotiating their work's co-emergence with other texts, which also includes intra-rogation, allusive situatedness and radical re-writing. Taken in turn, ever since the early twentieth century modernist literary works have interrogated (intra-rogated) ideological norms, shifting the equilibrium of creative practice through generic and formal experimentation. Other writers allusively situate their writing in relation to other works: Vietnam War film Apocalypse Now not only draws narratively upon Joseph Conrad's Heart of Darkness, but situates this through intra-textual references to TS Eliot's The Wasteland. Alternatively, works like Aimé Césaire's re-writing of The Tempest through a post-colonial lens subvert well-known stories, myths and archetypes for political ends.

Through the Weather Glass is my own intra-formal-generic-textual response to climate change. It is my own attempt to do 'everything' as one critic commented, which pushed me to the limit of my creative capacities. It 
is written in hybrid form, shifting between fantasy travel writing, lyric poetry, collage, and documentary photography, as a means of enacting the intra-formal 'cutting' and 're-cutting' of climate change. Thus, for example, the black and white photography operates in creative tension with the 'fantastic' narrative:

Icarus mesmerised herself on the dashed white clew leading ahead of them. One dash, two, three... 'Wake up!' W suddenly yelled.

Icarus juddered awake, almost throwing them into the headlong path of a passing truck:

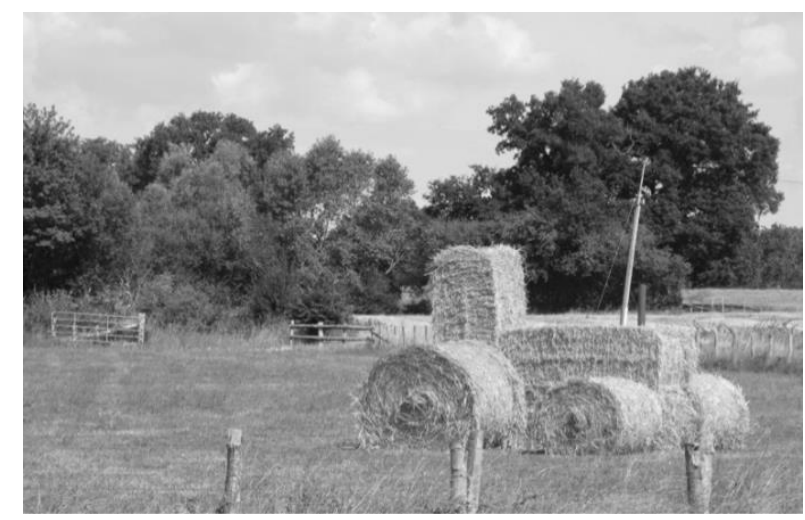

Meanwhile, open form and concrete poetry, and visual text materialise cuts on the page, while the rhythmic interspersal of lyric poetry and narrative prose enacts the refractive dynamics of meaning-making and change:

On the way out of town a paint-spattered decorator called out to ask them where they were headed. Icarus read the curved beginnings of the tabloid headline, rolled in his palm:

\section{WHAT THE...?!}

before replying 'Shropshire'. It was a more immediately achievable destination than Athens after all, and if she had to be tasked with climate change, then it was as likely to happen there as anywhere.

We drew our labyrinths with clues of salt la via salaria

a vapour trail upon the sky or the dashes down the middle of the road...(35) 
Rather than an Aristotelian narrative arc, the wandering structure is more characteristic of picaresque novels such as Gulliver's Travels or Don Quixote. Yet this is only one of many genres Through the Weather Glass works between, to further include autobiography, fantasy, magic realism, comedy, the quest narrative and travel writing, in a dynamic of on-going generic re/negotiation. Far from these genres being called into the service of a pre-established 'message', the experimentation seeks to destabilise the climate genre and create space for new ideas and approaches. Furthermore, these alternative genres are themselves changeable and will be 'recut' differentially during application. While seeking publication, one agent enquired where Through the Weather Glass might sit in the bookshop, and was not reassured by my response that it might go anywhere since it seeks to intra-rogate the notion of genre (and particularly the climate genre) itself! But it's not that Through the Weather Glass is uninterested in its relationship with other texts. On the contrary, not only does it intra-rogate the climate 'genre', its playful spirit draws allusively from Lewis Carroll, while its climate rewriting of the Icarus myth further extends the work of a significant number of artists who have viewed his tale of hubris and overweening pride as particularly pertinent to the twentieth and twentieth-century contexts.

\section{iii. performatively real}

While we have witnessed post-feminism, post-queer theory, post-structuralism, and post-colonialism (and indeed moved beyond the postmodern into the post-postmodern), one might be forgiven for sometimes thinking postmodernity had passed the environmental movement and its literature by. If, for Jean François Lyotard (1984), modernity is the quest to subdue the world through modern technology, then are our attempts to subdue climate change not an extension of this project, and 'representing' climate change in writing its literary equivalent? Climate change presents particular representational challenges, on account of its operation over vast geographic and time scales, its intangibility to the senses and inaccessibility to scientific measurement (Trexler \& Johns-Putra 185), thus epitomising Lyotard's notion of 'the unpresentable' (Lyotard 78). Yet most of the climate change oeuvre side-steps this formal challenge by representing either the current climate mitigation agenda or its catastrophic consequences. The aim, in common with the 'dominant frame', is to represent climate change's reality, in both current and future manifestations: as if the 'reality' of the 
'unpresentable' can be neutrally extrapolated from physical evidence into future scenarios. Yet when this manoeuvre is accomplished, what is really represented is an ideological perspective, informed by the metanarrative of neo-liberal, capitalist advancement and human progress.

Karen Barad is equally critical of representationalism, for its metaphysical individualist assumptions that, 'that which is represented is held to be independent of all practices of representing' (46). And within the entangled context of 'more climate change', this critique is acutely felt. In its place, Barad advances an interpretation of performativity involving practices of doing combined with 'direct material engagement'...dynamic practices that play a constitutive role in the production of objects and subjects and matter and meaning.' (49 \& 53) Thus, Barad's understanding of performativity is not simply epistemological; the processes of doing are themselves materially and semantically ontological. Furthermore, 'reality' is reconfigured as 'agential realism': 'not about representations of an independent reality but about the real consequences, interventions, creative possibilities, and responsibilities of intra-acting within and as part of the world.' (37) Applying Barad's theories to climate change, questions of 'reality' shift from proving and communicating the (incontrovertible) evidence, to considering our active role, and the creative possibilities involved, in doing (and thereby re/making) it. Scale becomes a question of experimental formal negotiation. Barad's notion of 'space-time' (437), involving enfolding the past-present-future of time-place into the present moment, offers writers exciting opportunities for exploding our previous linearity. Meanwhile, an alternative 'content' proposes itself, interested in how we intra-vene, and what we can create / change: how we can performatively enact new realities through materially engaged processes of doing. This 'content' is admittedly vast and undefined, in contrast to the closure I associated with the climate oeuvre, for what has opened up is a condition of 'more climate change' characterised by possibility.

When I first conceived of my European cycle expedition, I was concerned that it might turn out to have no relevance to climate change. On the contrary, one key finding has been to fundamentally reconceive of climate change itself as a journey which we perform every day. My expedition was simply an extended metaphor of my own journey staged through the mythological persona of Icarus: 
Icarus closed her eyes to realise the feeling of blood flowing from her head to her toes to her heart. She was used to inhabiting the forms of others on her quests to earth - to becoming the hybrid of Icarus and the identity she had assumed, with the combined knowledge and experience of both. And for the purposes of this climate change quest, her own myth and Lucy's life were to become one, and what would be would be, and be done with it? (2015 29)

A number of other 'journeying' texts have helped me creatively realise this 'finding' in innovative ways. While the looking glass world of Tweedle-dum and Tweedle-dee, the Jabberwocky, Humpty Dumpty, and the Red and White Knights and Queens is not the 'reality' to which we are accustomed, the reversing qualities of the mirror provide the conceptual process for readers to imaginatively make (non)sense of Alice's subsequent adventures. Of course Alice will struggle to win a running race with the Red Queen when everything works backwards - and who is to say that Carroll's performative version of non-progress is any more or less real than how we frame progress more usually?

Experimental travel writing also has much to offer. Again, what I don't have in mind are books like High Tide, which recounts Mark Lynas's international quest for the geographical evidence of, and human suffering caused by, climate change. Lynas overtly seeks to discover and 'prove that climate change is real and already underway' as a persuasive 'means to an end' (307). Yet while many of the scenes he describes are genuinely environmentally and humanitarianly devastating, he does not examine the ideological baggage he brings to representing them (and thereby making them in this ideological image), a colonializing trait he shares with much traditional travel writing. In contrast, Robert Pirsig's Zen and the Art of Motorcycle Maintenance and Bruce Chatwin's The Songlines offer a self-reflexively aware version of travel-writing which writers might bring to their climate 'journeys'. Pirsig's intra-generic travelogue performs a complex staging of his philosophical exploration of 'quality' in the context of his own mental and emotional breakdown. The story of a motorcycle ride with his son symbolises this broader journey, complicated by the persona of Phaedrus: the book both materialises 'quality' in rhetorical form, while simultaneously laying bare its philosophical and (in his case) 
personal failings. In The Songlines, Chatwin's narrator realises that the most pressing question is what is implied by, and what ideological baggage he brings to, the process of his own making of Aboriginal culture. In other words, the novel stages an intense critique of travel writing through an intra-rogative performance of it, in which what is made is most fundamentally that which is unmade:

It is good to collect things, but it is better to go on walks. (Anatole France)

My possessions fly away from me. Like locusts they are on the wing, flying...

(A lament on the destruction of Ur).

Returning to my own practice, writing the story of my cycle expedition as a straightforward piece of travel writing was never an option. Instead, taking Pirsig and Chatwin's lead, Through the Weather Glass is keenly aware of how it performs and re-makes climate change as it goes. Furthermore, Icarus's journey through the weather glass stages a similar dynamic to Alice's mirror - enabling readers to take the leap in imagination necessary to enter the reality of this world. In this alternate reality, not only does Wings the bicycle come to life, so do a range of other 'characters'. Real and fantasy, present day and historical, events are seamlessly interwoven such as to blur the distinctions between them, while enfolding the past-future-now into the present moment. I did cycle along a Greek motorway but I didn't encounter Apollonius of Tyana living homeless beneath a flyover. And far from seeking to persuade, Through the Weather Glass manifests itself as an openended invitation to readers to conduct their own processes of enquiry:

\footnotetext{
'Thank you,' [Icarus] said [to the weather glass, having hung it from a branch of an olive tree]. 'For absolutely everything. But I must leave you here where you might be of some help to other travellers - as a memento of our acceptance of the eastern rise and the western fall of the northern hemisphere sun. May other travellers voyage through you and see what I have seen. May others experience the world from the perspective of the sky. For surely our only hope resides there.' (256)
}

Even post-publication, the performative journey continues. Throughout 2016 an interactive installation version went on UK tour, involving a bike-powered TV, an animated Google Earth film of the route and a set of willow wings. The emphasis was on participation, with members of the public invited to perform weather 
glass world through pedalling, and to formulate their own responses on paper feathers to pin to Icarus's wings. Inevitably the installation provoked a range of responses, but a dominant theme was to note how, by approaching climate change in radically new ways, participants have come away with a renewed sense of hope.

\section{Part III - with conclusion nor end}

Where Mark Lynas straightforwardly refers to 'means to an end' (307), premised upon fears that climate change really might be humanity's 'end', teleological notions are inevitably problematic for a world of 'more climate change'. For where an emphasis has been laid on process and material change, how can we ever draw conclusions (a question as relevant to this article as to the journeys and creative texts in question)? Through the Looking Glass stages this problematic in a characteristically playful and performative manner, with Alice abandoning her ambitions of becoming 'Queen' by literally pulling the tablecloth from under her coronation dinner:

'I can't stand this any longer!' she cried, as she jumped up and seized the tablecloth with both hands: one good pull, and plates, dishes, guests, and candles came crashing down together in a heap on the floor. (234)

Chatwin's narrator's 'destination' formally fragments, while his concluding words conjure the only ending left available in a world devoid of meaning (as previously understood): ‘They knew where they were going, smiling at death in the shade of the ghost-gum.' (293) In turn, Pirsig's book ends well before the motorcycle expedition's conclusion - 'trials never end' - but at the point he and his son have come to realise the significance of their journey over its destination. 'Unhappiness and misfortune are bound to occur as long as people live, but there is a feeling now, that was not here before, and is not just on the surface of things but penetrates all the way through: we've won it. It's going to get better now. You can sort of tell these things.' (411) Qua Barad, it isn't that there can be no conclusions, for boundaries are being re/created all the time. The key realisation is that these 'endings' are provisional and real, but only momentarily realised, and inherently 
changeable.

By coining this a post-climate change manifesto, I pose a question keenly related to concepts of progress and 'endings'. If postmodernity is 'modernity in its nascent state' (Lyotard 79), then what might a post-climate change culture look like, as climate change in its nascent state? This poetic manifesto has been offered as a provisional response, based on the idea that climate change is not a (catastrophic) end in time, but rather a constant process of emergence, renewal, and re-nascence: an on-going journey(s) which we are constantly performing and which will never end, and which is as applicable to the scientific as to the cultural context. Through the Weather Glass is my creative attempt to realise this, and indeed Icarus herself recognises the provisional nature of 'endings' and 'beginnings' in her concluding thoughts, having finally managed to radically reconfigure her hubristic fate:

There were no destinations...And there were no ends. Just another flight to another place, and onwards, wherever her curiosity might take her, and she would take this trusty reminder of her bicycle with her, all the way. No matter how many times she had fallen during this quest, the world kept going, on and on and... why if Icarus ever did fall again, which there was no chance of, but if she did? (320)

So, returning full circle back to where we started: 'what if' climate change? 'What if' what is needed right now is not less climate change, as is commonly assumed, but rather more of it? We have travelled far from the closure involved in accounts of apocalypse, catastrophe and our frantic attempts to mitigate change. Instead, this article has asked what it might really mean to take climate change seriously - what the evidence of climate change implies for how humanity might intra-act with and from it (differently) in all contexts, and during which improvisation and playfulness will prove key. John Cage once described his work as 'purposeless play...an affirmation of life - not an attempt to bring order out of chaos nor to suggest improvements in creation, but simply a way of waking up to the very life we're living.' (95) It is something of this spirit which informs both this paper and the creative work from which it springs. If climate change is a journey, then how do wish to travel, what kind of a (provisional) world do we seek to re-make along the way, and what might it make of us? In a world of 'more climate change' there will be far more Sunday afternoon wanders, open-ended 
creative (and scientific) experiments, new approaches to creative work, research and criticism, more questions asked along the way, and humanity will have been unsettled once and for all from its position of mastery. Of course, these 'conclusions' themselves invite intra-rogation, and the possibility of change. But for now, since endings are impossible, and because I refrain from having the final word, I leave this to a participant of my Through the Weather Glass installation, whose sentiments concisely capture the ethos of the 'more climate change' world which this article proposes:

Do not fear change. Change is what fulfils us all. Never stand still...learn to fly! 


\section{Works cited}

Apocalypse Now. Directed by Francis Coppola, United Artists, 1979

Astley, Neil, editor. Earth Shattering: Ecopoems. Bloodaxe Books, 2007

Atwood, Margaret. The Year of the Flood. Virago Press, 2010

Awel Aman Tawe, editors. And This Global Warming. Roynetree Press, 2012

Barad, Karen. Meeting the Universe Halfway: Quantum Physics and the Entanglement of Matter and Meaning.

Duke University Press, 2007

Burnett, Lucy.

--- 'Firing the Climate Canon: A critique of the literary genre of climate change'. Green Letters, Vol 22, Issue 2, forthcoming 2018

--- Through the Weather Glass (and what Icarus Found There). Knives Forks and Spoons Press, 2015

Cage, John. Silence. Marion Boyars, 1987

Carroll, Lewis. Alice's Adventures in Wonderland and Through the Looking Glass. Penguin Books, 1998

Cervantes, Miguel de. Don Quixote. Wordsworth Classics, 1993

Césaire, Aimé. A Tempest, translated by Richard Miller. Theatre Comms Group, 2002

Cha, Theresa Hak Kyung. Dictee. University of California Press, 2001

Chatwin, Bruce. The Songlines. Vintage, 1998

Clark, Nigel. 'Volatile Worlds, Vulnerable Bodies: Confronting Abrupt Climate Change.' Theory, Culture E Society, Vol 27 (Issue 2/3), 32-54, 2010

Conrad, Joseph. Heart of Darkness. Oxford World's Classics, 2002

Crichton, Michael. State of Fear. Harper Collins, 2005

Danielewski, Mark Z. House of Leaves. Doubleday, 2001

Derrida, Jacques. Writing and Difference. Routledge, 2001

Eliot, TS. Collected Poems 1909-1962. Faber \& Faber, 2002

Frow, John. Genre. Routledge, 2005

Gardner, Martin. The Annotated Alice. Penguin, 2001

Glass, Matthew. Ultimatum. Atlantic Books, 2009

Gore, Al. An Inconvenient Truth: the Planetary Emergency of Global Warming and What We Can Do About It. Bloomsbury Publishing, 2006

Hall, Sarah. The Carhullan Army. Faber \& Faber, 2007

Heise, Ursula. Sense of Place and Sense of Planet: The Environmental Imagination of the Global. Oxford University Press, 2009

Hulme, Mike. Why We Disagree About Climate Change. Cambridge University Press, 2009

Jensen, Liz. The Rapture. Bloomsbury, 2009

Kuypers, Jim A. Rhetorical Criticism: Perspectives in Action. Lexington Press, 2009

Lynas, Mark. High Tide: How Climate Crisis is Engulfing our Planet. Harper Perennial, 2005 
Lyotard, Jean-Francois. The Postmodern Condition: A Report On Knowledge, translated by Bennington \& Massumi. Manchester University Press, 1984

McCarthy, Cormac. The Road. Picador, 2006

McEwan, Ian. Solar. Jonathan Cape, 2010

McIntosh, Alastair. Hell and High Water: Climate Change, Hope and the Human Condition. Birlinn Ltd, 2008

Monbiot, George.

--- 'Civilisation ends with a shutdown of human concern. Are we there already?' The Guardian, 30

October 2007, guardian.co.uk/commentisfree/2007/oct/30/comment.books?INTCMP=SRCH.

--- Heat: How We Can Stop the Planet Burning. Penguin Books, 2007b

Morton, Timothy.

--- 'Ecology as Text, Text as Ecology.' Oxford Literary Review, Vol 32:1, 1-17, 2010a

--- The Ecological Thought. Kindle Edition. Harvard University Press, 2010b

Munden, Paul, editor. Feeling the Pressure. The British Council, 2008

Pauchari, RK \& A Resinger, editors. Climate Change 2007: Synthesis Report. Contribution of Working Groups I, II and III to the Fourth Assessment Report of the Intergovernmental Panel on Climate Change. IPCC, 2007

Pirsig, Robert M. Zen and the Art of Motorcycle Maintenance. Vintage, 2004

Poet in the City, editors. Trees in The City: Poems About The Need for Action on Climate Change. Axon Publishing, 2007

Reese, Stephen, Oscar Gandy \& August Grant, editors. Framing Public Life: Perspectives on Media and Our Understanding of the Social World. Taylor \& Francis, 2001

Queneau, Raymond. The Flight of Icarus, translated by Barbara Wright. One World Classics, 2009

Robinson, Kim Stanley. Sixty Days and Counting. Harper Collins, 2007

Sinclair, Iain. Lud Heat and Suicide Bridge. Vintage, 1995

Self, Will. The Book of Dave. Penguin Books, 2007

Snow, David A. and Robert D. Benford. 'Ideology, Frame Resonance, and Participant Mobilization.' International Social Movement Research 1, 197-217, 1998

Sterling, Bruce. Heavy Weather. Phoenix, 1995

Swift, Jonathan. Gulliver's Travels. Penguin Books, 2003

Swngedouw, Erik. 'Apocalypse Forever? Post-political Populism and the Spectre of Climate Change?' Theory, Culture and Society, Vol 27 (Issue 2 /3), 214-33, 2010

The Day After Tomorrow. Directed by Peter Emmerich, 20 ${ }^{\text {th }}$ Century Home Fox Entertainment, 2004

Trexler, Adam \& Adeline Johns-Putra. 'Climate Change in Literature and Literary Criticism.' Wiley Interdisciplinary Reviews: Climate Change. Vol. 2 185-200, 2011

Wallace, Mark. 'Definitions in Process, Definitions as Process / Uneasy Collaborations: Language and Postlanguage Poetries.' Flashpoint Magazine, Issue 2, flashpointmag.com/postlang.htm

Winterson, Jeanette. The Stone Gods. Penguin Books, 2007

Yates, Cliff. 'Flying: A Poetics.' Troubles Swapped for Something New edited by Rupert Loydell, Salt, 28-37, 2009 